\title{
Impact of Perception of Performance Appraisal Politics on Affective Commitment: Mediate Effect of Perception of Organizational Support and Differentiation Effect of Perception Attribution
}

\author{
JIAO Zhen-qi ${ }^{1, a}$, ZHANG Guang-jin ${ }^{2, *}$ \\ ${ }^{1}$ Public Administration School, China University of Geosciences, Wuhan, China \\ ${ }^{2}$ Public Administration School, China University of Geosciences, Wuhan, China
}

\begin{abstract}
Performance appraisal politics is widespread in the organization. It provides a new perspective for improving performance appraisal to study its effects on employee attitudes. In addition, its influence on employees' attitude is still blank. This paper utilizes questionnaire survey and structural equation model to study the impact of different types of perception of performance appraisal politics on employees' affective commitment. The result shows that different types of perception of performance appraisal politics have different effect on employees' attitude. Perception of public-private concerned high ratings has positive effect, however, perception of organizational-interested low ratings, selfish high rating perception and self-interested low rating perception have negative effect. The effect strength was decided by employee's attribution about perception of performance appraisal politics. Perception of organizational support played a complete mediate role in the impact of perception of performance appraisal politics on employees' affective commitment. Based on the findings of the study, managers can reduce employees' negative perception of performance appraisal politics and passive consequences by restricting estimators' selfish leniency and conscious oppressive evaluation, guiding employees to attribute performance appraisal politics positively and enhancing perception of organizational support.
\end{abstract}

\section{Introduction}

The traditional assumption is that appraisers should have no bias or prejudice in the performance evaluation process, which is justified as a pure desire by current studies. In actual management, performance appraisal politics, which means that appraisers deliberately distort assessment results, is a common phenomenon (Longenecker \& Gioia, 2000; Arshad et al., 2013; Wu Zheng, Sun Jianmin, 2006; Chen Yunyun, Zhang Yichi, 2008).

Some people think that performance appraisal politics has everything to lost but nothing to gain (Arshad et al., 2013), while others argue that we should never be absolute in this point (Wu Zheng, Sun Jianmin, 2006; Wang Hongyan, 2017). Regarding the advantages and disadvantages of performance appraisal politics, Wang Hongyan and Chen Zhixia (2015) analyzed the root causes of the conflict and pointed out that the motivations of appraisers should be taken into account when studying the impact of performance appraisal politics on employee's attitudes and behaviors. In fact, some studies have made preliminary distinctions on performance appraisal politics, and found that it has different effects on

aemail:2985037875@qq.com

*Corresponding author's e-mail: zhangguangjin@cug.edu.cn employees (Wang Hongyan, 2017; Poon, 2004; Sogra et al., 2009; Zhao Shusong, 2012). According to the existing literature, there are very few empirical studies on the effects of performance appraisal politics, and there are obvious differences in their conclusions. One possible reason may be that performance appraisal politics is roughly categorized. Longenecker and Ludwig (1990) have divided performance appraisal politics into four types, but some studies simply them into two types. The simplification and combination result in ambiguity and cross-border information, which led to instability of unclear variables in different studies. This research applied the four types of performance appraisal politics systems against background of China and analyzed its impact on employee's attitudes. This research is elaborated on the basis of previous studies and is the localized application of those studies.

At the same time, in an era when the employment relationship tends to be more and more unstable, the loyalty of employees to the organization is very important (Fan Yun et al., 2013). Organizational commitment is viewed as a measurement of employees' psychological state and has triggered a large number of studies, scholars in the field of performance appraisal politics also start to pay attention to this issue (Sogra et al., 2009). In the context performance appraisal politics prevails in actual 
work, a small number of studies and explorations are obviously not enough; in addition, performance appraisal politics is a part of organizational politics, and the existing literature of organizational politics found that the impact of organizational politics on organizational commitment is not straightforward, instead there is a transmission process of psychological changes (Zhang Juncheng, Ling Wenquan, 2013; Rong \& Cao, 2015). Therefore, is there any intermediate link in the evaluation process? This paper focuses on affective commitment, the most important component of organizational commitment, and studies the affecting mechanism of performance appraisal politics on it. It is a useful attempt to uncover the relationship between them.

Therefore, there are two goals of this research, namely, identifying the differential impacts of different types of performance appraisal political perceptions on employees' affective commitments, and the mechanism of the influence process. It will be of great significance for organizations to manage performance appraisal politics in different ways and enhance employees' positive attitudes.

\section{Research hypothesis}

The institution, standards and management methods of an organization are always implemented and reflected by its agents at all levels. Therefore, when the organization is personalized, employees regard the attitudes and behaviors of their superiors, especially their immediate superiors, as the organization's attitudes and behaviors, and then they will respond to the organization accordingly (Lin Yinghui, Cheng Ken, 2016; Choi et al., 2015). Based on this, performance appraisal is a typical activity of superior managing the subordinates, and Perception of Performance Appraisal Politics (PPAP) is supposed to have an impact on their attitudes toward organizations.

\subsection{The impact of PPAP on affective commitment}

Scholars' views on the nature of performance appraisal politics are not completely consistent, but most studies hold a bifurcated view (Wu Zheng, Sun Jianmin, 2006; Wang Hongyan, 2017; Poon, 2004; Sogra et al., 2009; Zhao Shusong, 2012). Based on the work of Chen Yunyun and Zhang Yichi (2008), Zhang Guangjin (2018) conducted an in-depth study on the political structure of performance appraisal in China and concluded four types of performance appraisal politics. Public-private concerned high rating model refers to the evaluation action that appraisers give higher ratings to subordinates for the interests of both organizations and individuals. For example, appraisers give evaluations to subordinates to encourage them to work harder. Hypocritical and selfish high rating model refers to the evaluation action that appraisers give high ratings to subordinates for their own benefits. For example, appraisers give high marks to those who benefit the appraisers themselves. Self-interested low rating model refers to the evaluation action that appraisers deflate evaluation for their own interests. For example, appraisers give low ratings to those subordinates who threat their positions. Organizational-interested low rating model refers to the evaluation action that appraisers, as agents of the organization, are forced by the situation to give low marks to the evaluated. For example, they give low evaluations to subordinates in order to reduce costs and obtain competitive advantages. There is more than one political system of performance appraisal in China, which provides room for discussion on the differentiated effects of performance appraisal politics.

Researchers often understand organizational commitment from different perspectives, but they basically interpret it as an affirmative psychological tendency. Although scholars have many different views on the components of organizational commitment, affective commitment is the dimensional that is the closest to organizational commitment (Luo Jing, 2007; Wisanupong \& Michael, 2017). Therefore, this paper focuses on analyzing the possible impact of the perception of performance appraisal politics on affective commitment.

Regarding to the affecting factors of affective commitment, degree of challenge, role pressure and job insecurity cannot be ignored (Fan Yun et al., 2013). According to the role pressure theory, the role pressure at work mainly comes from role conflict and role ambiguity. When there is a big difference in one's job expectations and requirements, role conflict will occur; when the employee is not clear about what he should do, his role will be blurred. From the perspective of performance appraisal politics, when employees perceive the existence of hypocritical and selfish high rating politics and self-interested low rating politics, they will think that evaluation results are less related to work performance, and that the ideal appraisal results cannot be achieved simply by improving their own skills or working hard, but need complex interpersonal relationships, especially establishment and maintenance of personal relationships with leaders (Luo Hua, An Shiquan, 2011). This is different from the role requirements and formal expectations of organizations, which is expecting employees to focus on their own work; meanwhile, employees often feel confused and don't know how to choose in whether to strive to become masters at work or to become leaders' "darling". This confusion will result in role pressure and reduce employees' feelings for organizations. Job insecurity refers to a sense of helplessness in maintaining the current job and its key characteristics (Ni Dan, Zheng Xiaoming, 2018; Van et al., 2018). In the process of performance evaluation, when employees perceive the existence of public-private concerned high rating politics, they will think that their superiors will give themselves more tolerance, whether for organization or individual interests, and therefore they will have a higher level of security sense and devote more feelings to the organization; when employees perceive the existence of organizational-interested low rating politics, they will think that even if they do a good job, their superiors will give harsh evaluations and deliberately belittle their performance, which will have an adverse effect on themselves. As a result, they will be anxious and afraid of performance appraisal, have a sense of insecurity on their jobs and devote less feelings to their organization 
(Brown et al., 2010). Based on this, the following research hypotheses are proposed:

H1: Perception of public-private concerned high rating politics has a positive effect on affective commitment, while perception of organizational-interested low rating politics, perception of hypocritical selfish high rating politics and self-interested low rating politics have negative effects on affective commitment.

\subsection{The mediating effect of perceived organizational support and the differentiation effect of perceptual attribution}

Perceived organizational support (POS) is a view of employees on how the organization views their contributions and cares about their interests. In short, it is the support that employees perceive from the organization (Nikhil \& Arthi, 2018). Although people have different understandings on the connotation of perceived organizational support, work support, value recognition and concern for interests are widely recognized as three components of it. According to the theory of perceived organizational support, remuneration, working conditions, and superior support have an important impact on organizational support (Liu Zhui et al., 2018). Performance appraisal is not only an evaluation result for employees, it also involves remuneration and the allocation of organizational resources. When employees perceive the existence of public-private concerned high rating politics, they will consider that the organization is providing them with opportunities to improve their work, and gives preferential treatment to them in terms of remuneration, which reflects the organization's support for their work and concern for their interests; when employees perceive the existence of organizational-interested low rating politics, they will think that the organization deliberately reduces their due compensation and development opportunities through degrading evaluation, and their value is not recognized, which harms their interests and reduces their perceived organizational support (Wang Hongyan, 2017). When employees perceive the existence of hypocritical and selfish high rating politics and self-interested low rating politics, they will think that the organization ignores their work commitment and legitimate interests, their contributions are not recognized, and the organization has not created a fair working environment and uses employees' performance appraisal as a tool to play with power and factional struggles, which will undermine their perceived organizational support (Saad \& Elshaer, 2017; Liu Xiaoping, Wang Chongming, 2001). Based on this, the following hypotheses are proposed:

$\mathrm{H} 2$ : perception of public-private concerned high rating politics has a positive effect on POS, while perception of hypocritical and selfish high rating politics, organizational-interested low ratings and perception of self-interested low ratings have negative impacts onPOS.

Are the effects of PPAP on perceived organizational support the same? The answer to this question is helpful to distinguish between the primary and the secondary in the governance of performance appraisal politics, and attribution theory has direct inspiration to this question. Attribution theory believes that if individuals have different understandings on the causes of the same phenomenon, they will have different feelings and attitudes (Cai Shuangli, Gao Yang, 2019). Studies have found that employees often use attribution models similar to interpersonal communication to infer perceived organizational support. If they think that the support provided by the organization is voluntary rather than externally enforced, for example, not through government policies or labor unions, they will have a higher degree of perceived organizational support (Rhoades \& Eisenberger, 2002).

The general discussion on the attribution of perceived organizational support by Chinese scholars Liu Xiaoping and Wang Chongming (2001) provides us with a good analysis thought. They believe that employees' perceived organizational support is largely affected by attribution. Normally, people tend to attribute the causes to internal source when results meet expectation, that is, attributing the results that meet their expectations to their own abilities and work commitments. Comparing with attributing results to organization, their perceived organization support degree will be low. People tend to attribute the causes to external source when results don't meet expectations, because they are likely to look for reasons outside of themselves, such as organization management, other people, luck, etc. Comparing with attributing to themselves, their perceived organizational support degree will be higher.

Inspired by the above analysis idea, this paper further elaborated the attributions. Specifically, there are two types of attributions, one factor is dominated or controlled by the organization itself, and the other is uncontrollable factor, that is organization is forced by adverse situation or employees. If employees attribute the results that don't meet their expectations to factors that are dominated or controlled by organization, they will have stronger sense of perceived organizational support, comparing with attributing to those results to uncontrollable factors that organization is forced by adverse situation or employees themselves. In the field of perception of performance appraisal politics, the evaluation results are more likely to meet the expectation of appraisees in public-private concerned high rating politics. According to self-service psychology (Wen, 2018), employees will think that the results are owned to their own abilities and efforts; in addition, public-private concerned high rating is also regarded as a win-win strategy adopted by the organization for the purpose its own interests. In organizational-interested low rating politics, hypocritical and selfish high rating politics and self-interested low rating politics, evaluation results often cannot meet appraisees' expectations, but they would have different attributions. In organizational-interested high rating politics, they tend to believe that low rating is a passive strategy adopted by the organization out of situation and for sustainable development. In hypocritical and selfish low rating politics and self-interested low rating politics, employees tend to believe that evaluation results are 
actively determined by the organization itself and that organization fails to respect employees and undermines fairness. Based on the above facts that employees tend to attribute rating results to themselves or organization's decision out of situation in public-private concerned high rating politics and that employees attribute rating results to organization itself in hypocritical and selfish high rating politics and self-interested low rating politics, they following hypotheses are proposed:

H3: Perception of public-private concerned high ratings has a positive impact on POS, perception of organizational-interested low ratings has a negative impact on perceived organizational support, but their effects is less than that of hypocritical and selfish high rating perception and self-interested low rating perception.

Social exchange theory can well explain the motivations and behaviors of employees. According to this theory, the relationship between employees and the organization is an exchange relationship by nature, and its interaction strategy does not deviate from reciprocal norms, that is, the organization provides employees with a platform for development, work support and labor compensation, and employees are loyal to the organization, work hard in return and help the organization achieve greater development (Rhoades \& Eisenberger, 2002). Kim et al. (2016) further believe that when employees perceive organizational support, they will be prompted to have a sense of responsibility to care about the organization's interests and make contributions to the organization; in addition, the organization's support for employees, such as satisfying their needs in respect, recognition and care, will also enhance their sense of belonging and emotional bond with the organization. The findings of Malik et al. (2016) show that a certain level of support from an organization can inspire the same degree of organizational commitment. The study of Moon \& Choi (2017) also confirms that cares and supports in finance and professional development provided by the organization will help employees improve their chances of success and enhance their affective commitment to the organization. Based on this, the following hypotheses are proposed:

H4: POS has a positive impact on affective commitment.

To sum up, when employees perceive the existence of performance appraisal politics in the organization, they will judge organizational support based on what type of performance appraisal politics they are in, whether the organization recognizes their value, whether it care about their interests and whether it supports their work, and their emotional bond is further affected under reciprocal psychological mechanism. Based on this, the following research hypotheses are proposed:

H5: POS has a mediating effect in the process that PPAP effects employees' affective commitment.

\section{Research design}

In this research, data was collected through questionnaire survey, and SPSS24.0 and AMOS24.0 were used to test the reliability and validity of the questionnaires as well as the single source bias to ensure data quality. Then the correlation coefficient between the variables was calculated, clarifying the feasibility of causality analysis in the next step. Finally, the structural equation model was used to test hypotheses H1 to H5.

\subsection{Sample information}

In this study, more than 1,000 questionnaires were distributed through on-site, e-mail, or intermediaries. Participants were asked to give scores (in five-points system) to their perceived performance appraisal politics, perceived organizational support, and affective commitment. 876 questionnaires were returned and a screening work was carried out. Questionnaires with scribble answers, obvious regularity in answer options, and excessive data missing were eliminated. Finally, 768 questionnaires were confirmed to be valid. Those valid samples are shown in Table 1. It can be seen that these samples are typical and representative.

Table 1. sample information $(n=768)$.

\begin{tabular}{|c|c|c|c|c|c|c|c|}
\hline & Category & Number & Ratio\% & & Category & Number & Ratio\% \\
\hline \multirow{2}{*}{ Gender } & Male & 428 & 56.2 & \multirow{3}{*}{ age } & $\leqq 35$ & 278 & 37.0 \\
\hline & Female & 334 & 43.8 & & $36-45$ & 308 & 41.0 \\
\hline \multirow{3}{*}{ Position } & $\begin{array}{c}\text { Middle } \\
\text { management }\end{array}$ & 53 & 7.0 & & $\geqq 46$ & 166 & 22.0 \\
\hline & Supervisor & 160 & 21.0 & \multirow{6}{*}{$\begin{array}{l}\text { Organizati } \\
\text { on } \\
\text { type }\end{array}$} & Government & 82 & 11.2 \\
\hline & $\begin{array}{c}\text { Ordinary } \\
\text { employees }\end{array}$ & 547 & 72.0 & & Public sector & 126 & 17.1 \\
\hline \multirow{4}{*}{$\begin{array}{l}\text { Education } \\
\text { level }\end{array}$} & Master's degree & 33 & 4.5 & & $\begin{array}{c}\text { Social } \\
\text { organization }\end{array}$ & 40 & 5.4 \\
\hline & $\begin{array}{c}\text { Bachelor's } \\
\text { degree }\end{array}$ & 236 & 32.2 & & $\begin{array}{c}\text { State-owned } \\
\text { enterprises }\end{array}$ & 100 & 13.6 \\
\hline & $\begin{array}{c}\text { Junior college } \\
\text { degree }\end{array}$ & 295 & 40.1 & & Private enterprise & 291 & 39.5 \\
\hline & $\begin{array}{c}\text { Technical } \\
\text { secondary } \\
\text { school or High } \\
\text { school degree }\end{array}$ & 142 & 19.4 & & $\begin{array}{l}\text { Foreign-capital } \\
\text { enterprise }\end{array}$ & 71 & 9.7 \\
\hline
\end{tabular}




\begin{tabular}{c|c|c|c|c|c|c|c}
\hline & $\begin{array}{c}\text { Junior high } \\
\text { school degree or } \\
\text { bellow }\end{array}$ & 28 & 3.8 & & Else & 26 & 3.5 \\
\hline
\end{tabular}

Note: Missing values are not counted

\subsection{Questionnaire and data quality analysis}

The scales of variables in this study adopts existing scales in the literature. Among them, the performance appraisal politics perception scale is a simplified version based on the questionnaire compiled by Zhang Guangjin (2018). The scale of public-private concerned high ratings is composed of six items, including the item of "giving high ratings to subordinates to incentive them to work harder." The scale of hypocritical and selfish high ratings consists of six items, including "giving high ratings to those subordinates who can bring him/her special benefits." The scale of self-interested low rating consists of four items, including "giving low ratings to those subordinates who do not belong to his/her circle." The scale of organizational-interested low ratings is composed of four items, including "giving low ratings to subordinates because of too much external competitive pressure." Scale of perceived organizational support comes from a six-item questionnaire by Luo Jing (2007), including typical question of "if I need specific help, our organization will be willing to help." The affective commitment scale comes from a five-item questionnaire by Ling Wenyuan et al. (2000), including typical question of "I have deep feelings for the organization."

In order to test the quality of the questionnaire and single source bias, this paper carried out confirmatory factor analysis and Alpha coefficient calculation on the measured variables. The results are shown in Table 2 and Table 3.

Table 2. Confirmatory factor analysis of variables.

\begin{tabular}{c|c|c|c|c|c|c|c|c}
\hline Fit Index & $\chi^{\mathbf{2}}$ & $\chi^{\mathbf{2} / \mathbf{d f}}$ & RMSEA & TLI & NFI & CFI & PNFI & PCFI \\
\hline $\begin{array}{c}\text { single-factor } \\
\text { model }\end{array}$ & 3644.298 & 8.397 & 0.098 & 0.635 & 0.631 & 0.659 & 0.589 & 0.615 \\
\hline $\begin{array}{c}\text { two-factor } \\
\text { model }\end{array}$ & 2312.653 & 5.341 & 0.075 & 0.786 & 0.766 & 0.800 & 0.713 & 0.745 \\
\hline $\begin{array}{c}\text { three-factor } \\
\text { model }\end{array}$ & 1660.643 & 3.853 & 0.061 & 0.859 & 0.832 & 0.869 & 0.771 & 0.806 \\
\hline $\begin{array}{c}\text { six-factor } \\
\text { model }\end{array}$ & 965.376 & 2.304 & 0.041 & 0.936 & 0.902 & 0.942 & 0.813 & 0.849 \\
\hline
\end{tabular}

Note: The single-factor model means that all survey questions are attributed to one factor; the two-factor model means that performance appraisal politics perception is attributed to one factor, and perceived organizational support and affective commitment are attributed to another factor; the three-factor model means that performance appraisal politics perception, perceived organizational support and affective commitment are attributed to one factor respectively; the six-factor model is that perception of public-private concerned high ratings, perception of hypocritical and selfish high ratings, perception of self-interested low ratings, perception of organizational-interested low ratings, perceived organizational support and affective commitment are attributed to one factor respectively.

It can be seen from Table 2 that the fitting index of the six-factor model is relatively ideal, while other models are inferior to this model, and their relative fitting indexes are also lower than the recommended standard (Wu Minglong, 2017), so the six variables in this study have good discriminative validity. Table 2 also shows that all the fitting indices of the single-factor model are relatively poor, which means that the data of the six variables in the measurement does not come from a single factor; when exploratory factor analysis is performed on all variables, no single factor has been isolated, and the variance extracted of the first factor is $14.3 \%$, which is far below $25 \%$, so it can basically be considered that single source bias is not significant (Wang Yongyue, Duan Jinyun, 2015). The Alpha value of each variable is listed on the diagonal positions in Table 3 , which are all greater than 0.8 , indicating that the measurement questionnaire has high reliability.

\section{Data analysis results}

\subsection{Descriptive statistics and correlation analysis of variables}

The SPSS24.0 was used to calculate the mean and standard deviation of the 6 variables involved in this study, and the correlation analysis between the variables was performed. The results are shown in

Table 3. Descriptive statistics and correlation analysis of variables.

\begin{tabular}{c|c|c|c|c|c|c}
\hline & $\mathrm{x} 1$ & $\mathrm{x} 2$ & $\mathrm{x} 3$ & $\mathrm{x} 4$ & $\mathrm{y} 1$ & $\mathrm{y} 2$ \\
\hline $\mathrm{x} 1$ & 0.89 & & & & & \\
\hline $\mathrm{x} 2$ & $0.11^{*}$ & 0.85 & & & & \\
\hline
\end{tabular}




\begin{tabular}{c|c|c|c|c|c|c}
\hline $\mathrm{x} 3$ & $-0.21^{* *}$ & $0.24^{* *}$ & 0.86 & & & \\
\hline $\mathrm{x} 4$ & -0.06 & $0.12^{*}$ & 0.08 & 0.85 & & \\
\hline $\mathrm{y} 1$ & $0.16^{* *}$ & $-0.32^{* *}$ & $-0.31^{* *}$ & $-0.21^{* *}$ & 0.87 & \\
\hline $\mathrm{y} 2$ & $0.13^{* *}$ & $-0.17^{* *}$ & $-0.19^{* *}$ & $-0.14^{* *}$ & $0.43^{* *}$ & 0.86 \\
\hline $\begin{array}{c}\text { Std. } \\
\text { Deviation }\end{array}$ & 1.07 & 0.76 & 0.53 & 0.47 & 0.67 & 0.56 \\
\hline Mean & 3.46 & 3.18 & 2.27 & 1.92 & 2.85 & 2.71 \\
\hline
\end{tabular}

Note: Alpha value on the diagonal line refers to the reliability of the variables. $x 1$ represents perception of public-private concerned high ratings; $\mathrm{x} 2$ represents perception of hypocritical and selfish high ratings; $x 3$ represents self-interested low ratings; $\mathrm{x} 4$ represents organizational-interested low ratings; y1 represents perceived organizational support; y2 represents affective commitment. * means significance level $<0.05, * *$ means significance level $<0.01$.

It can be seen from Table 3 that perception of public-private concerned high ratings has a significant positive relationship with perceived organizational support and affective commitment, perception of hypocritical and selfish high ratings, perception of self-interested low ratings and perception of organizational-interested low ratings have significant negative relationships with perceived organizational support and affective commitment. The result lays the foundation for the research hypothesis testing.

\subsection{Hypothesis testing}

On the basis of correlation analysis and according to the recommendations of Baron and Kenny (1986), AMOS24.0 was used to test hypotheses H1 to H5. The direct effect of PPAP on affective commitment is examined first, then the direct effect of PPAP on perceived organizational support is examined, and the mediating effect of perceived organizational support in the process that PPAP affects affective commitment is examined at last. The structural equation simulation result of the effect of PPAP on affective commitment is shown in Figure 1 and Table 4.

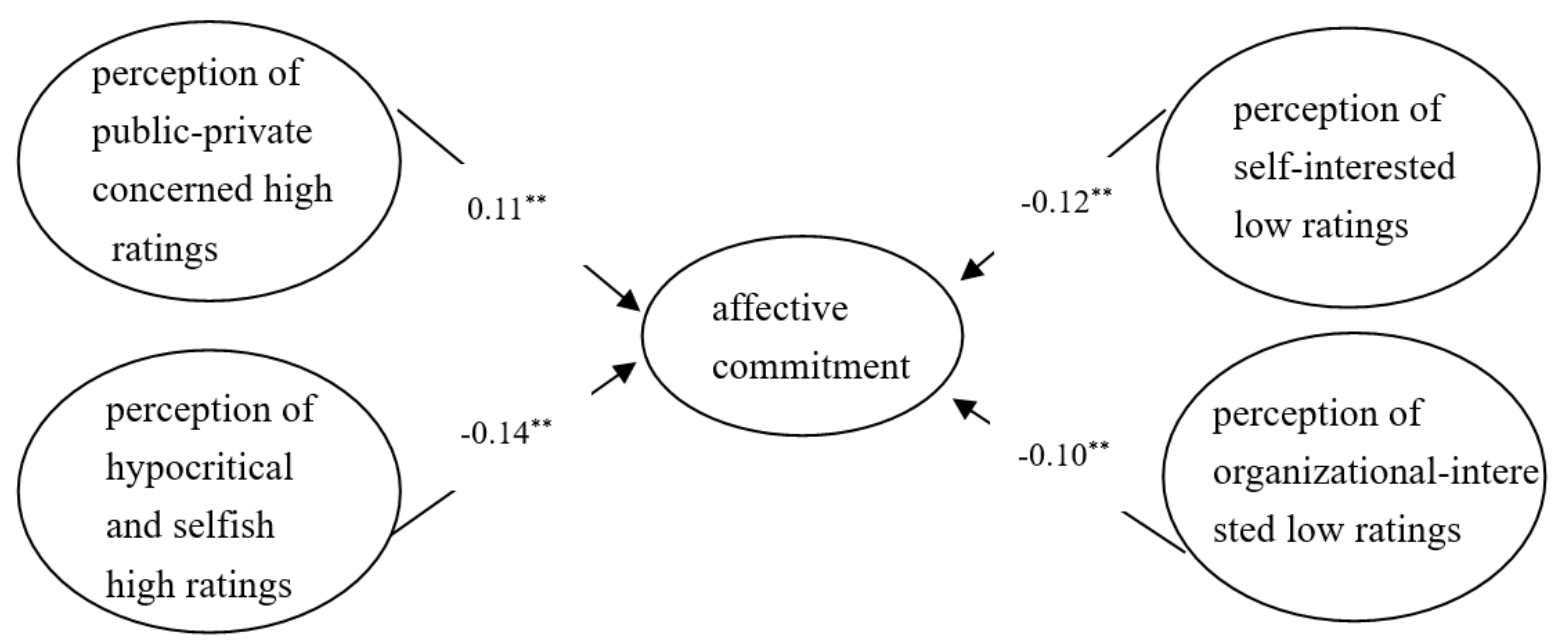

Figure 1. The direct effect of PPAP on affective commitment.

Table 4. The goodness of fit of the direct effect model of PPAP on affective commitment.

\begin{tabular}{c|c|c|c|c|c|c|c|c}
\hline Fit Index & $\chi^{2}$ & $\chi^{2} / \mathbf{d f}$ & RMSEA & TLI & NFI & CFI & PNFI & PCFI \\
\hline statistic & 836.340 & 3.156 & 0.053 & 0.910 & 0.888 & 0.920 & 0.785 & 0.813 \\
\hline
\end{tabular}

It can be seen from Figure 1 that perception of public-private concerned high ratings has a significant positive impact on affective commitment, with a standardized path coefficient of 0.11 . The perception of hypocritical and selfish high ratings, perception of self-interested low ratings and perception of organizational-interested low ratings have significant negative impacts on affective commitment, with standardized path coefficients of $-0.14,-0.12$ and -0.10 respectively. Table 4 also shows that the simulation index of the direct effect of PPAP on affective commitment is within an acceptable range ( $\mathrm{Wu}$ Minglong, 2017), and thus hypothesis 1 has been verified.

The structural equation simulation result of the effect of PPAP on perceived organizational support is shown in Figure 2 and Table 5. 


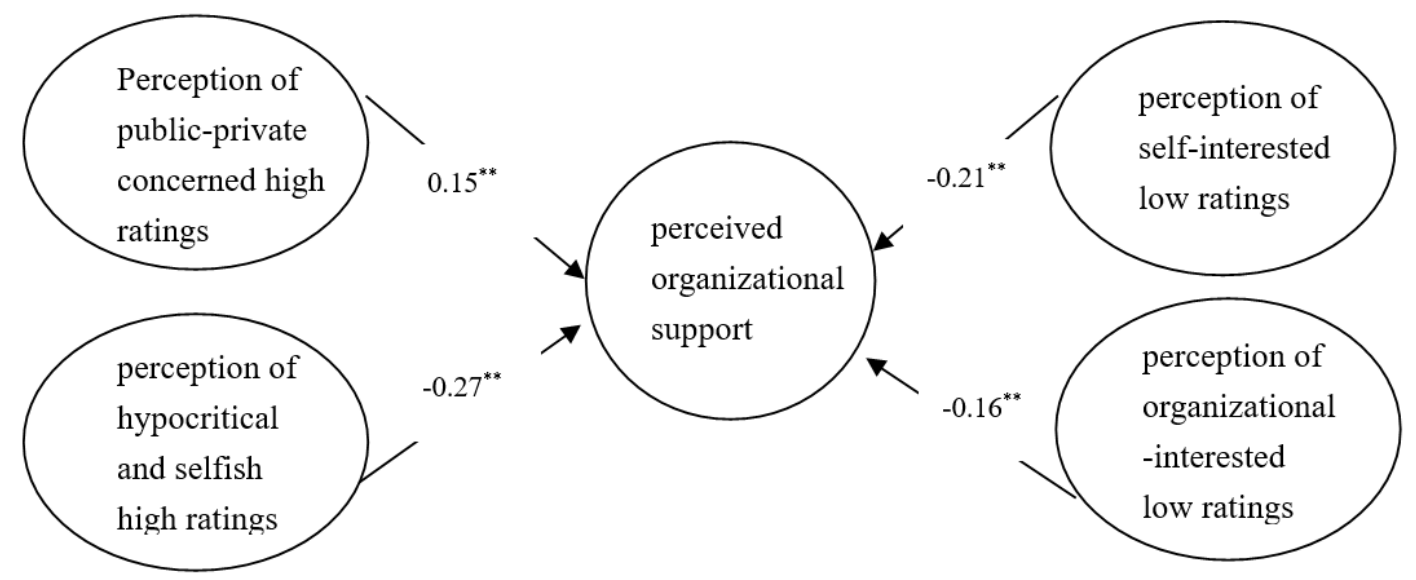

Figure 2. The effect of PPAP on perceived organizational support.

Table 5. The goodness of fit of the effect model of PPAP on perceived organizational support.

\begin{tabular}{c|c|c|c|c|c|c|c|c}
\hline Fit Index & $\chi^{\mathbf{2}}$ & $\chi^{\mathbf{2}} / \mathbf{d f}$ & RMSEA & TLI & NFI & CFI & PNFI & PCFI \\
\hline statistic & 815.847 & 2.823 & 0.049 & 0.937 & 0.917 & 0.944 & 0.815 & 0.840 \\
\hline
\end{tabular}

It can be seen from Figure 2 that perception of public-private concerned high ratings has a significant positive impact on perceived organizational support, with a standardized path coefficient of 0.15 . The perception of hypocritical and selfish high ratings, perception of self-interested low ratings and perception of organizational-interested low ratings have significant negative impacts on perceived organizational support, with standardized path coefficients of $-0.27,-0.21$ and -0.16 respectively. The effects of public-private concerned high rating perception and organizational-interested low rating perception are greater than that of hypocritical and selfish high rating perception and self-interested low rating perception. Table 5 also shows that the simulation index of the direct effect of PPAP on perceived organizational support is good $(\mathrm{Wu}$ Minglong, 2017), and thus hypotheses 2 and 3 have been verified.

The mediating effect of perceived organizational support in process that PPAP affects employees' affective commitment is shown in Figure 3 and Table 6. 0.06

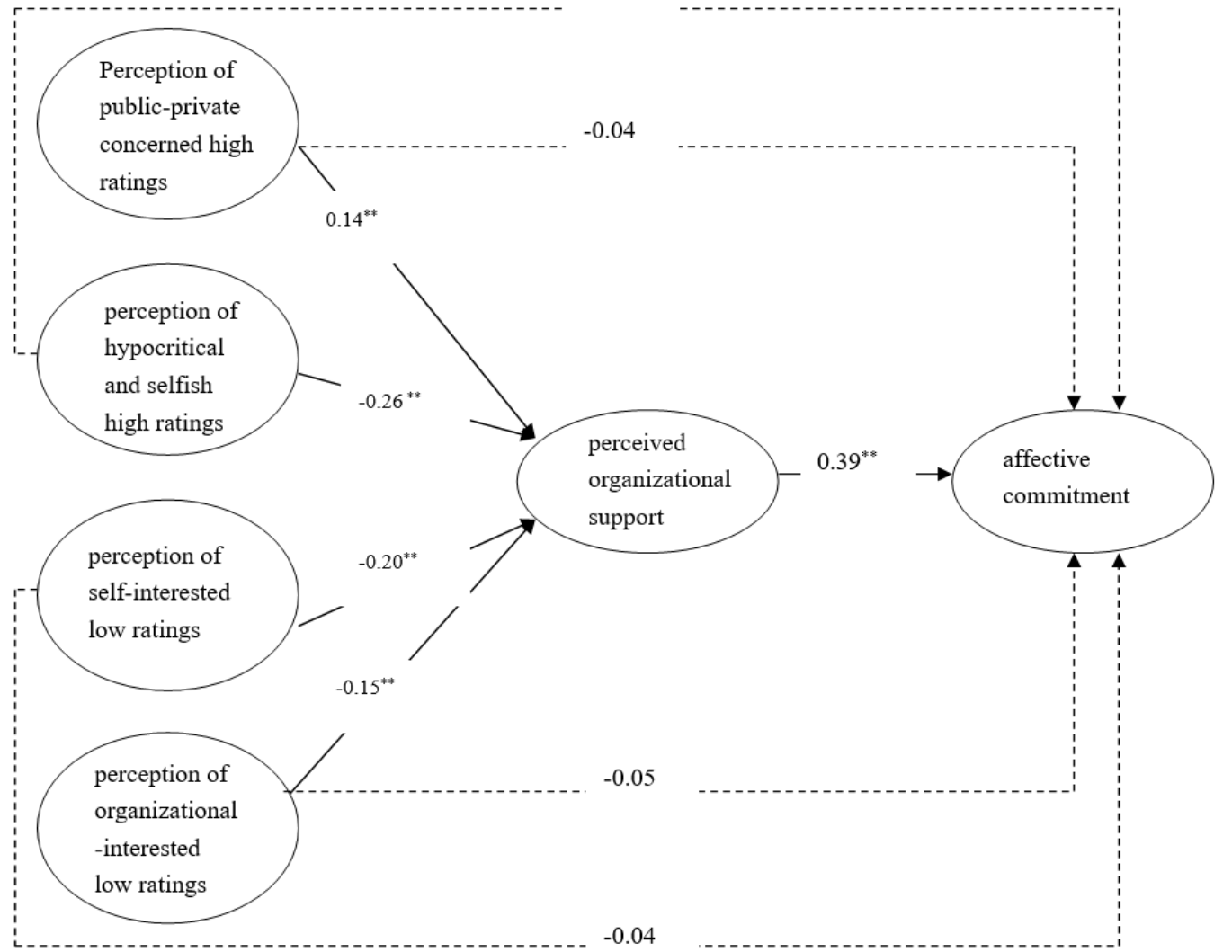

Figure 3. The mediating effect of perceived organizational support in the influence of PPAP on affective commitment. 
Table 6. The goodness of fit of the mediation model of the influence of PPAP on affective commitment.

\begin{tabular}{c|c|c|c|c|c|c|c|c}
\hline Fit Index & $\chi^{\mathbf{2}}$ & $\chi^{\mathbf{2}} / \mathbf{d f}$ & RMSEA & TLI & NFI & CFI & PNFI & PCFI \\
\hline statistic & 941.912 & 2.248 & 0.040 & 0.943 & 0.911 & 0.948 & 0.821 & 0.855 \\
\hline
\end{tabular}

When perceived organizational support is added to the model of the direct effect of PPAP on affective commitment, it can be seen from Table 6 that the overall fitting index of the model is good, and most fitting indices are better than that in Table 4, which means the model has significantly improved (Wu Minglong, 2017). Figure 3 lists the path coefficients of variables. It can be seen that perceived organizational support has a significant impact on affective commitment, with a standardized path coefficient of 0.39 . All the four types of performance appraisal politics perceptions have significant impacts on perceived organizational support, with standardized path coefficients of $0.14,-0.26,-0.20$ and -0.15 respectively. Perceived organizational support has a mediating effect in the process that PPAP affects employees' affective commitment. Comparing Figure 3 and Figure 1, it can be found that after perceived organizational support is added, the impacts of the four types of performance appraisal politics perceptions on affective commitment are not so significant, with standardized path coefficients of 0.06 , $-0.04,-0.05$, and -0.04 respectively. Therefore, it is concluded that perceived organizational support plays a completely mediating role in the process that PPAP affects employees' affective commitment. Thus hypotheses 4 and 5 have been verified.

Based on the above empirical tests, the verification results of the hypotheses proposed are summarized in Table 7. It can be seen from Table 7 that the research hypotheses are all valid.

Table 7. Research hypotheses testing summary.

\begin{tabular}{c|c|c|c|c|c}
\hline $\begin{array}{c}\text { Research } \\
\text { Hypothesis }\end{array}$ & Hypothesis 1 & Hypothesis 2 & Hypothesis 3 & Hypothesis 4 & Hypothesis 5 \\
\hline Test Result & true & true & true & true & true \\
\hline
\end{tabular}

\section{Conclusions and Enlightenment}

\subsection{Research conclusions and theoretical contributions}

This research has three new findings: first, different performance appraisal politics perceptions have different impacts on employees' perceived organizational support and affective commitment. Specifically, perception of public-private concerned high ratings provides employees with a sense of job security and improvement opportunities, reflecting organization's care and support for employees, so it has a positive impact on affective commitment and perceived organizational support; perception of hypocritical and selfish high ratings and perception of self-interested low ratings cause role conflicts and ambiguity for employees, and organizations fail to create a fair working environment; perception of organizational-interested low ratings brings employees a sense of job insecurity and organizations fail to recognize the value of employees. All of the three perceptions have negative impacts on affective commitment and perceived organizational support. Second, the attribution of PPAP is an important mechanism that differentiates the strength of their perceived organizational support. In private-public concerned high rating politics, employees attribute evaluation results to their own abilities and the goodwill of the organization; in organizational-interested low rating politics, employees attribute evaluation results to the unwilling behavior of the organization compelled by adverse situations. Therefore, these two perceptions have relatively little influence on employees' perceived organizational support. However, in hypocritical and selfish high rating politics and self-interested low rating politics, employees are more likely to attribute evaluation results to arbitrary political playing, and thus it has a greater negative impact on employees' perceived organizational support. Third, PPAP has an indirect impact on employees' affective commitment, and perceived organizational support plays a completely mediating role between the two. In other words, PPAP affects employees' perceived organizational support. Under the psychological mechanism based on social exchange, it will further affect their emotional bond with the organization.

\subsection{Management Enlightenment}

The enlightenment of this research for management mainly includes: (1) Organizations should take active measures to restrain the negative performance appraisal politics, so as to reduce employees' perception of negative performance appraisal politics. First of all, it is necessary to strictly enforce the responsibility of appraisers, improve evaluation dispute resolution mechanism, and increase the cost of performance evaluation violations, so as to prevent appraisers from behaving selfishly in performance appraisal. Secondly, it is necessary to build an open performance appraisal system, make clear the standards of performance appraisal and improve the degree of formalization in the process, thus the space of the occurrence of performance appraisal politics is squeezed, and appraisers have no opportunity to execute negative performance appraisal politics. Finally, it is 
necessary to cultivate a rule-oriented organizational atmosphere and select management cadres who possess the virtues of ability, integrity and fairness and who can put their moral behavior at priority at all levels, thus appraisers won't feel like executing negative performance appraisal politics. (2) Organizations should strengthen attribution guidance of PPAP. In the whole process of performance management, especially in performance coaching and performance feedback, organizations should introduce the development situation, internal and external environment they face and the trend of performance appraisal to employees, help them form reasonable expectations for their evaluation, guide them to attribute evaluation results that cannot meet their expectations to external factors and reduce their negative feelings for the organization. (3) Organizations should enhance employees' perceptive organizational support to enhance their affective commitment. Organizations can pay more attention to the actual interests of employees, recognize their value, improve working conditions, properly authorize under certain conditions, increase employees' work autonomy and challenge, etc., so that employees can perceive the organization's strong support, and thus are more connected with organizations in emotion and make more contributions.

\subsection{Research limitations and prospects}

In a sense, this paper is an exploratory research, and its shortcomings are obvious. First, this paper only discusses the impact of PPAP on affective commitment, but in practice organizations are very concerned about employees' resignation and performance, and thus it is obvious that further study on the impact of PPAP on employees' behavior should be conducted; second, only influencing process of PPAP on affective commitment is explored in this paper, without considering boundary conditions of the effect. For example, when employees have proficient political skills, will their attitudes toward the organization change if they have the same political perception? Researches have shown that employees with high political skills will find themselves in an organization with a strong political atmosphere and they also prefer such organizations (Gao Zhonghua, Zhao Chen, 2014), which provides new thinking; last, cross-sectional data is used in this paper to test the causality, but no completely firm conclusion is reached in theory, follow-up research can be further verified by longitudinal data.

\section{Acknowledgments}

National Natural Science Foundation of China, "Research on Political Behavior of Performance Appraisal in the Context of China: Structure, Formation Mechanism and Influence" (71402172); Supported by National Natural Science Foundation of China, "Research on Organizational Competitive Cooperation and Breakthrough Innovation Mechanism Based on Cross-boundary Sharing", (71832004); Research on Political Perception of Performance Appraisal "Structure,
Determents and Influencing Mechanism" (CUGW150403).

\section{References}

1. Longenecker C O, Gioia D A. (2000) confronting the politics in performance appraisal. Business Forum, 25(6): 17-23.

2. Arshad M A., Masood M T., Amin G. (2013) effects of performance appraisal politics on job satisfaction, turnover intention and loyalty to supervisor: study with reference to the telecom organizations of Pakistan. International Review of Management \& Business Research, 2(3):653-673.

3. Z. Wu, JM. Sun. (2006) Politics in performance appraisal. Research on Economics and Management, 27(2):21-26.

4. YY. Chen, YC. Zhang. (2008) Political Consideration in Performance Appraisal_-On the Basis of Content Analysis in China Contex. Management Review, 20(9):39-50.

5. HY. Wang. (2017) The Effects of Performance Appraisal Politics on Employee's Creative Behavior: The Role of Leader-Member Exchange Relationship Differentiation. Contemporary Economic Management, 39(10):56-66.

6. HY. Wang, ZX. Chen. (2015) A Literature Review of Performance Appraisal Politics. Foreign Economics \& Management, 37(9):57-67.

7. Poon J M L. (2004) effects of performance appraisal politics on job satisfaction and turnover intention. Personnel Review, 33(3): 322-334.

8. Sogra K J, Shahid A I, Najibullah S. (2009) organizational outcomes of the employees' perceptions of performance appraisal politics: a study on executive MBA students in Bangladesh. South Asian Journal of Management, 16(3):43-60.

9. SS. Zhao. (2012) Empirical Research on the Influence of Performance Appraisal Politics to Individual Knowledge Sharing. Nankai Business Review,15(3):150-160.

10. Longenecker C O, Ludwig D. (1990) ethical dilemmas in performance appraisal revisited. Journal of Business Ethics, 9(12):961-969.

11. Y. Fan, X. Zhang, J. Yan. (2013) A Review of Organizational Commitment Based on the Theory Evolution. Management Review, 25(1):101-113.

12. JC. Zhang, WQ. Ling. (2013) The Impacts of Perceptions of Organizational Politics on R\&D Employees' Work Attitudes: An Empirical Analysis Based on Conservation of Resources Theory. Science of Science and Management of S.\& T, 34(2):134-143.

13. Rong Z, Cao G. (2015) a framework for research and practice: relationship among perception of organizational politics, perceived organization support, organizational commitment and work engagements. Open Journal of Business \& 
Management, 03(4):433-440.

14. YH. Lin, K. Chen. (2016) Leader-member Exchange and Employees' Unethical Pro-organizational Behavior: A Differential Mode Perspective. Journal of Management Science, 29(5):57-70.

15. Choi S B, Ullah S E, Kwak W J. (2015) ethical leadership and followers' attitudes toward corporate social responsibility: the role of perceived ethical work climate. Social Behavior and Personality: an International Journal, 43(3):353-365.

16. GJ. Zhang. (2018) Research on the Structure of Political Behavior of Performance Appraisal in China. Journal of China University of Geosciences(Social Sciences Edition), 18(6):154-168.

17. J. Luo. (2007) A Dissertation Submitted in Partial Fullment of the Requirements for the Degree of Doctor of Philosophy in Management. Huazhong University of Science and Technology. Wu Han.

18. Wisanupong P, Michael T F. (2017) does public service motivation always lead to organizational commitment? Examining the moderating roles of intrinsic motivation and ethical leadership. Public Personnel Management, 46(3) 211-238.

19. H. Luo, SQ. An. (2011) Analysis of political behavior in organizational performance appraisal. Human Resource Management, 6(3):38-39.

20. D. Ni, XM. Zheng. (2018) The Effect of Abusive Supervision on Moral Disengagement: Based on Self-Regulation Theory. Science of Science and Management of S.\& T, 39 (7):146-161.

21. Van H, Anahi N, Wendy D W. (2018) does job insecurity hinder innovative work behavior? a threat rigidity perspective. Creativity and Innovation Management, 2(1):19-29.

22. Brown M, Hyatt D, Benson J.(2010) consequences of the performance appraisal experience .Personnel Review, 39(3):375-396.

23. Nikhil S, Arthi J. (2108) perceived organizational support and work engagement: mediation of psychological capital - a research agenda. Social Science Electronic Publishing, 7(1):33-40.

24. Z. Liu, SD. Yan, HY. Jiang. (2018) The Effect of E-leadership on Employee Engagement_-Based on the Mediating Effect of Perceived Organizational Support. Soft Science, 32(7):65-69.

25. Saad S K, Elshaer I A. (2017) organizational politics and validity of layoff decisions: mediating role of distributive justice of performance appraisal. Journal of Hospitality Marketing \& Management, 26(8):805-820.

26. XP. Liu, CM. Wang. (2001) Organizational commitment and its formation process. Nankai Business Review, 2001, 4(6):58-62.

27. SL. Cai, Y. Gao. (2019) Ethical Relief and Attribution: Why do employees remain silent in the face of enterprise non-ethical behavior? Journal of Business Economics, 39(2):30-40.
28. Rhoades L, Eisenberger R. (2002) perceived organizational support: a review of the literature. Journal of Apply Psychology, 87(4):698-714.

29. Wen S. (2018) the effect of result publicity on self-serving attribution bias_— a social comparison perspective. Frontiers of Business Research in China, 12(1):7-8.

30. Kim K Y, Eisenberger R, Baik K. (2016) perceived organizational support and affective organizational commitment: moderating influence of perceived organizational competence. Journal of Organizational Behavior, 37(4):558-583.

31. Malik S Z, Kazmi S Z, Nadeem N. (2016) the effect of perceived organizational support on doctors' organizational commitment in Pakistan. Lahore Journal of Business, 4(2):73-92.

32. Moon J S, Choi S B. (2017) the impact of career management on organizational commitment and the mediating role of subjective career success. Journal of Career Development, 44(3):191-208.

33. WQ. Ling, ZC. Zhang, LL. Fang. (2000) The research on the structure model of Chinese employee's organizational commitment. Journal of Management Sciences in China, 3(2):76-81.

34. ML. Wu. (2017) Operation and Application of Structural Equation Model AMOS. Chongqing University Press. Chongqing.

35. YY. Wang, JY. Duan. (2015) How do political skills influence employee voice behavior: the role of relationship and performance. Management World, 31(3):102-112.

36. Baron R M, Kenny D A.(1986) the moderator-mediator variable distinction in social psychological research: conceptual, strategic, and statistical considerations. Journal of Personality \& Social Psychology, 51(6):1173.

37. ZH. Gao, C. Zhao. (2014) Does Organizational Politics at the Workplace Harm Employees' Job Performance? A Person-Organization Fit Perspective. Acta Psychologica Sinica, 46(8):1124-1143. 